\title{
Psychophysiological Responses of Firefighters to Emergencies: A Review
}

\author{
Fabrizio Perroni ${ }^{1, *, \#}$, Laura Guidetti ${ }^{3, \#}$, Lamberto Cignitti $^{2}$ and Carlo Baldari ${ }^{3}$ \\ ${ }^{I}$ School of Exercise and Sport Sciences (SUISM), Department of Medical Sciences, University of Turin, Italy \\ ${ }^{2}$ Italian Fire Fighters Corp, Italy \\ ${ }^{3}$ Department of Movement, Human and Health Sciences, University of Rome "Foro Italico", Italy
}

\begin{abstract}
Firefighters perform strenuous muscular works in hazardous environments and chaotic conditions, under time pressure and psychological stress. Various studies have shown high values of oxygen uptake, heart rate, blood lactate concentrations and salivary cortisol and A-Amylase in laboratory test, in real-life and simulated interventions of firefighters. These high values have been attributed to the combined effect of the metabolically active muscle, thermoregulatory strain and fatigue resulting from the protective gear and a self-contained breathing apparatus in addition to further supplementary overweight (i.e., lifting weights, rescuing victims). In order to protect health and safety of firefighters and victims during emergencies, high levels of cardiovascular endurance and strength in firefighters are strongly recommended. In fact, high levels of physical fitness showed to increase firefighters' work ability, safety and decreased risk of injury.
\end{abstract}

Keywords: Anxiety, cardiovascular diseases, heart rate, hormonal responses, self-contained breathing apparatus, thermal strain.

\section{INTRODUCTION}

Considerable information in the literature [1-5] has shown the work of the firefighters as the civilian employment with the highest variability of exposure to physical stress and risks. During the emergencies, the firefighters have to filter a large number of sensory stimuli (i.e., people in need, environmental events, movements of colleagues) that turn into specific reactions and actions. These actions and reactions occur in multiple forms characterized by several variables: space-time, duration, breaks, nature of the emergency (i.e. fire in an apartment or car accident), and biomechanics movement (i.e. running or climbing stairs).

Various studies [1, 5-17] documented that the combination of physical activity, unpredictable conditions, warm clothing and/or exposure to external heat sources causes an increased physiological and psychological stress. In addition, firefighters wear protective clothing (PC) and self-contained breathing apparatus (SCBA), which are heavy, thick, multilayered and bulky (i.e., $23 \mathrm{~kg}$ ). This overload can have adverse effects upon gait $(-25 \%$ of walk velocity), metabolic and thermoregulatory efficiency $(+20 \%$ strain), tolerance time to work $(-22 \%$ to low and $-75 \%$ to high intensity), fatigue and the risk of injury [4, 18-23].

Cady et al. [24] have shown that high levels of physical efficiency can help the firefighters to carry out tasks (i.e., the

*Address correspondence to this author at the University of Turin, Piazza Bernini 12, Turin, Italy: Tel: +39 0636733227; Fax: +39 0636733257;

E-mail: fabrizio.perroni@unito.it

"Both authors contribute equally lifting and carrying of the fire hose, transport equipment up and down the stairs, entering with force or transport in safety of victims) and are related to a decreased risk trauma.

Although physical stress and the workload of a real emergencies are difficult to measure, several authors have claimed that the firefighting causes a heart rate (HR) close to the maximum values $[5,12,16,17]$ with decrease in the stroke volume [12], and increase in the core temperature [5, $11,12]$, in the levels of blood lactate $[10,16,17]$ and psychological stress $[3,5,11,12]$. For this reason, it is recognized $[25,26]$ that firefighters must possess the physiological characteristics that enable them to respond to the emergencies. Study of Hammer et al. [27] emphasizes the need of a higher priority for firefighter fitness programs in order to best ensure the safety of firefighters and the public.

The aim of this review was to (a) examine evidence on the physical demands and the actual workload of firefighting, (b) identify the relative importance of the various contributing factors, and (c) make recommendations on physical programs and future research in this area.

A set of relevance criteria was developed a priori. The criteria required to be included were the job requirements and their implications in terms of physical, physiological and psychological aspects.

A search filter and electronic search strategy were developed in collaboration with a librarian with extensive experience in conducting systematic reviews. The search filter used a series of firefighter related keywords to extract potentially relevant articles from electronic databases: Medline, Psycinfo, Current Contents, Sportdiscus. All 
databases were searched for all languages and age groups and from the earliest records available. Duplicates between databases were identified and removed to create a master list.

\section{RISK FACTORS}

Several studies $[1,2,28]$ have shown that environmental and physical stress met by the firefighters can determine occupational hazards ranging from lesions to death. The high incidence of musculoskeletal and circulatory trauma [29-31] and premature death [32], has been attributed to the considerable physical and mental commitments [1, 4], overexertion and strain [33] imposed after completion of rescue operations. These traumatic events, often associated with subjective perception of physical and mental fatigue with repercussions on the private life [34], may be due to poor or even missing physical training.

For a five-year period [35], 368 on-duty U.S. firefighters died during emergencies: $39 \%$ of heart attacks, and $61 \%$ of other causes (i.e., burns, asphyxiation and motor vehicle related trauma). Each year, coronary heart disease (CHD) is the leading cause (90\%) of the death in firefighters with $45 \%$ during firefighters' activities [36, 37]. Karter and Molis [33] claimed that for every fatal on-duty heart disease event, there are an estimated 17 nonfatal events in the U.S. fire service.

Recent studies $[2,38,39]$ estimated that firefighters spent $1 \%$ to $5 \%$ of their time on fire activities, yet $32 \%$ of deaths occurred from CHD-related events during that time. Fernhall et al. [40] examining standard echocardiographic measures of cardiac size and performance in response to a $3 \mathrm{~h}$ firefighting training exercise have shown significant cardiovascular changes.

The high level of cardiovascular diseases (CVD) and mortality in the firefighters depends on the interaction of several factors such as sympathetic activation [3, 16], physical workload [41-43], heat [5,11,44], dehydration [11, $12,22]$, inadequate physical activity $[45,46]$, dietary habits [47-50], shift work [47, 51-53], smoke exposure [54, 55], noise [56] and psychological stress [12-14, 57, 58].

A study of Baur et al. [59] on the association between CVD factors and cardiorespiratory fitness in 968 firefighters showed that higher metabolic equivalents categories were significantly associated with lower diastolic blood pressure, body fat, triglycerides, low-density lipoprotein cholesterol and total/high-density cholesterol ratio, and higher highdensity lipoprotein.

\section{CARDIOCIRCULATORY STRAIN}

Among the different parameters studied, the maximum oxygen uptake $\left(\mathrm{VO}_{2 \max }\right)$ is the variable most frequently taken into consideration. In this sense, there are recommendations that require minimum values $V_{2} O_{2 \max }>33 \mathrm{ml} \mathrm{kg}^{-1} \mathrm{~min}^{-1}$, with preferably $>45 \mathrm{mlkg}^{-1} \cdot \mathrm{min}^{-1}$, to successfully complete a rescue protocol standard $[1,13,41,42,60]$. The single analysis of firefighters' activities showed that: climbing stairs with $\mathrm{PC}+\mathrm{SCBA}$ for 5 minutes required an average $\mathrm{VO}_{2}$ of $39.0 \mathrm{ml} \mathrm{kg}^{-1} \mathrm{~min}^{-1}$ [61], lifting and moving the hose required a $\mathrm{VO}_{2}$ of $23.4-25.7 \mathrm{ml}^{-1} \mathrm{~kg}^{-1} \mathrm{~min}^{-1}$, while the control of a flexible tube $\mathrm{a} \mathrm{VO}_{2}$ of $30.9 \mathrm{ml} \mathrm{kg}^{-1} \mathrm{~min}^{-1}$ (approximately 75 and $98 \%$ of $\mathrm{VO}_{2 \max }$ ) and to transport the equipment on the stairs a $\mathrm{VO}_{2}$ of $36.6-44.0 \mathrm{ml} \mathrm{kg}^{-1} \mathrm{~min}^{-1}$ [62]. Various studies $[6,62,63]$ have determined that immersion in the smoke (search and rescue) is the most challenging task faced by the firefighters. Perroni et al. [17] by analyzing simulated emergencies (i.e., child rescue; $250 \mathrm{~m}$ run; search and rescue; $250 \mathrm{~m}$ run) of 20 Italian firefighters have shown that $\mathrm{VO}_{2}$ consumption of the search and rescue was $56 \pm 6 \%$ compared to the total energy requirement of a simulated emergencies and was $67 \pm 16 \%$ compared to $\mathrm{VO}_{2 \max }$ evaluated in laboratory.

The HR has been analyzed in response to a real emergency $[14,64,65]$, to the sound of the alarm [66], to various activities of the firefighters [1] and to the use of SCBA [67, 68]. Several authors [9, 10, 14, 67, 69] have reported an HR, variable from 150 to $190 \mathrm{bmin}^{-1}$, attributable to environmental stress, work stress, and high psychological stress. In particular, in response to the distress call the HR rapidly increases with range from $84 \%$ to $100 \%$ of the individual maximum heart rate $\left(\mathrm{HR}_{\max }\right)$, equivalent to $63-97 \%$ of $\mathrm{VO}_{2 \max }$ [14]. HR increases during very hard work carried out for a shorter period of $15 \mathrm{~min}$ [9-11], and for a longer period [70], and remains high during the recovery phase [16, 17]. Indeed, Perroni et al. [17] showed that the values of $\mathrm{HR}$ and $\mathrm{VO}_{2}$ increased during the simulated emergencies and they remained elevated after $30 \mathrm{~min}$ of rest (HR: $108 \pm 15$ beats $\mathrm{min}^{-1} ; \mathrm{VO}_{2}: 8.86 \pm 2.67 \mathrm{ml}^{-1} \mathrm{~kg}^{-1} \mathrm{~min}^{-1}$ ) with respect to basal values (HR: $66 \pm 8$ beat $\min ^{-1} ; \mathrm{VO}_{2}$ : $4.57 \pm 1.07 \mathrm{ml} \mathrm{kg}^{-1} \mathrm{~min}^{-1}$. After short (352 $\left.\pm 42 \mathrm{~s}\right)$ simulated rescue of hospital patients, Von Heinburg et al. [71] have shown high values of $\mathrm{HR}\left(96 \pm 5 \%\right.$ of $\left.\mathrm{HR}_{\max }\right)$, perceived effort $(8.9 \pm 1.0)$, blood lactate concentrations $(13 \pm 3$ mmol $\left.\mathrm{L}^{-1}\right)$, and consumption of oxygen $\left(3.9 \pm 0.5 \mathrm{Lmin}^{-1}\right)$ in firefighters.

Rodriguez-Marroyoa et al. [72] analyzed the HR of firefighters during real wildfire suppression according to the type of attack performed (direct, indirect or mixed). They found significantly higher $\mathrm{HR}$ in direct and mixed versus indirect attacks and demonstrated that wildfire firefighting depends on the tactics chosen for performing the task.

In addition to physiological overload of the emergencies, firefighters wear PC+SCBA and use heavy equipment (i.e., ladders, fire hose lines, etc.). Indeed, Smith et al. [10] have shown high levels HR wearing PC while Manning and Griggs [73] observed a rapid increase in HR up to $70-80 \%$ of maximum values during the first minute wearing $\mathrm{PC}+\mathrm{SCBA}$.

Baker et al. [67] have compared the cardiorespiratory and thermal responses of two intensities of treadmill exercise (12 $\mathrm{min}$ ) in firefighters wearing $\mathrm{PC}$ and sports ensemble (SE). At $7 \mathrm{~km}^{-1} \mathrm{~h}^{-1}, \mathrm{VO}_{2}$ was significantly higher in $\mathrm{PC}(36.1-39.9$ $\left.\mathrm{ml} \mathrm{kg}^{-1} \mathrm{~min}^{-1}\right)$ than in SE and represented $74 \% \mathrm{VO}_{2 \max }$, while Bruce-Low et al. [68] have shown an increase of $39.8 \%$ wearing PC. Several authors [74-77] suggest that PC+SCBA used by the firefighters would negatively affect $\mathrm{VO}_{2 \max }$. In particular, Perroni et al. [77] by evaluating the $\mathrm{VO}_{2 \max }$ of firefighter recruits with step test performed with and without $\mathrm{PC}+\mathrm{SCBA}$, have shown that wearing the $\mathrm{PC}+\mathrm{SCBA}$ about $10 \%$ of firefighter recruits had failed to complete the step test.

Various authors $[1,14,78]$ have shown that good levels of aerobic power are useful to carry out fire fighting 
activities in relation to the use of $\mathrm{PC}+\mathrm{SCBA}$. Comparing $\mathrm{PC}$ with only shorts and a T-shirt, previous studies have shown a reduction of $25 \%$ of maximum power [79] and an increase of $\mathrm{VO}_{2}(11 \%)$ running on treadmill to $7 \mathrm{~km}^{-1}$ [67], while comparing PC with an outerwear, have reported a $50 \%$ increase of the metabolic load [70]. Faff and Tutak [80] have shown that when the environmental temperature is increased from $20{ }^{\circ} \mathrm{C}$ to $39{ }^{\circ} \mathrm{C}$ (humidity of $70 \%$ ), HR increases significantly with PC and fatigue manifests itself much faster. In this direction, various authors $[5,17]$ have stated that it is not possible to exclude that the progressive increase in $\mathrm{HR}$ is determined by changes in temperature regulators imposed by PC. A study by Eglin et al. [64] on a group of instructor firefighters showed increased levels of HR and internal temperature during exercise. The same authors hypothesized that these increments were attributed to dehydration, reduced heat tolerance and physical performance.

Given the nature of their duties, a physiological agerelated decline could be expected during the occupational period of firefighters. Baur et al. [59] have investigated the effect of increasing age on cardiorespiratory fitness in career of firefighters as well as the modifying effects of physical activity and adiposity. They found that cardiorespiratory fitness decline was greatly attenuated among leaner firefighters who reported more physical activity.

Cross-sectional studies on firefighters have shown a constant decrease in age-related [24], an annual decrease of 0.30 to $0.80 \mathrm{mlkg}^{-1} \cdot \mathrm{min}^{-1}$ in relative aerobic capacity between the age groups of 19 to 29 years and 50 to 59 years [81], 0.60 to $0.70 \mathrm{ml} \mathrm{kg}^{-1} \mathrm{~min}^{-1}$ between the age groups of 30 to 34 years and 50 to 54 years [82], a decrease in $\mathrm{VO}_{2 \max }$ values of $10 \mathrm{mlkg}^{-1} \mathrm{~min}^{-1}$ after 20 years [83], and a $45 \%$ reduction in $\mathrm{VO}_{2 \max }$ of the firefighters of 20 and 60 years [84]. Punakallio et al. [85] have studied aerobic capacity and predictors as exercise, smoking, and drinking habits in 78 male Finnish firefighters (aged 30 to $44 \mathrm{yrs}$ ) at 3- and 13year follow-ups. They found that the average annual change in absolute $\left(\mathrm{L} \cdot \mathrm{min}^{-1}\right)$ and weight-related $\left(\mathrm{mlkg}^{-1} \mathrm{~min}^{-1}\right)$ aerobic capacity was $-1.12 \%$ and $-1.33 \%$. Exercising at least 4 to 5 times a week was the best protective factor, and regular smoking and more than 15 units of alcohol a week were risk factors for decline in aerobic capacity.

In this direction, the admission and retention of English firefighter recruits, are subject to a limit of maximum aerobic power of $42 \mathrm{ml} \mathrm{kg}^{-1} \mathrm{~min}^{-1}$ and require additional training for those who fail to reach that value [26]. Wynn and Hawdon [86] wanted to determine whether a reduction in, or elimination of, a defined cardiorespiratory standard for firefighter was influenced by a number of occupational and health-related outcomes. The results of this study showed that the removal of a defined standard cardio is associated with adverse effects on health and employment outcomes.

\section{THERMOREGULATORY ASPECTS}

Various studies $[10,87]$ have shown that working in a hot environment generates greater physiological and psychological stress compared to a thermo-neutral environment. Exposure to heat during firefighting varies in severity, duration and irregular intensity. The duration of exposure to heat is often determined by the SCBA and is usually limited to about $20 \mathrm{~min}$. Eglin and Tipton [88] have documented how the firefighting instructors were exposed to heat for $40 \mathrm{~min}$ during training exercises while Ruby et al. [89] have shown that the duration of fire suppression ranged from 12 to 18 hours. In addition, the firefighters' environment may have extreme and dangerous temperatures, varying between $67^{\circ} \mathrm{C}$ and $190{ }^{\circ} \mathrm{C}$ but can reach more than $200{ }^{\circ} \mathrm{C}[9-11,64,90]$. The study of Angerer et al. [69] wanted to determine cardiocirculatory and thermal strain during fire suppression in firefighters and compare it with the strain during medical and performance evaluations. During the fire suppression, body core temperature increased by $0.9 \pm 0.5{ }^{\circ} \mathrm{C}$ and blood parameters changed accordingly. In this direction, laboratory studies [67, 91-95], simulated activities [42, 68] and actual emergencies [14, 64, 65] showed thermal increase due to heat radiated by the fire, physical activity and use of $\mathrm{PC}+\mathrm{SCBA}$. It is observable an increased internal temperature $\left(1.5{ }^{\circ} \mathrm{C}\right)$ when subjects wearing $\mathrm{PC}+\mathrm{SCBA}[44]$ in temperate environment.

In relation to clothing, Taylor [96] recorded temperatures of flashover of $91{ }^{\circ} \mathrm{C}$ (internal coat), $59{ }^{\circ} \mathrm{C}$ (outer sleeve), $54{ }^{\circ} \mathrm{C}$ (inner sleeve) and $42{ }^{\circ} \mathrm{C}$ (chest) during simulated activities. In this study, the authors have shown that the clothes in contact with the skin provide an important layer of insulation. Previously, White and Hodous [97] and White et al. [98] had studied the effects of different sets protective of firefighters and they explained that fatigue occurred more quickly, both at low intensity and in high intensity test, when the subjects wore the $\mathrm{PC}+\mathrm{SCBA}$. PC+SCBA have caused a high degree of stress characterized by fatigue that occurred after 25 min of working at low intensity, and after 4 min of high intensity work. Carter et al. [44] have shown that a period of firefighting exposure greater than $10 \mathrm{~min}$ without adequate rest and cooling may lead to a significant accumulation of heat stress and fatigue during further firefighting activity, irrespective of physical prowess.

Various studies [68, 93, 99, 100] have shown that the $\mathrm{PC}+\mathrm{SCBA}$ does not favor thermoregulation, increases skin and internal temperature and decreases the rate of heat transfer due to the limited permeability to water vapor. Furthermore, the increase in the rate of sweating causes dehydration $[101,102]$ and reduction of the heat dissipation from the body [103, 104]. Taylor et al. [105] have investigated the overall impact upon performance during a maximal, job-related obstacle course trial and an incremental treadmill test to exhaustion (with and without protective equipment). The PC reduced exercise tolerance by $56 \%$ on a treadmill, with the oxygen consumption reserve being $31 \%$ lower while for the obstacle course, performance declined by $27 \%$.

Research on thermoregulation in the firefighters and other professions that use PC has shown a continuous increase of rectal temperature during recovery in contrast with the decrease in HR $[10,106]$. These events increase the threat of heat stress. To improve the regulation of body temperature, some authors [107, 108] have previously assumed the greater effectiveness of a PC that presents lower thermal protection. Carter et al. [44] have shown that an appropriate recovery can be achieved by removing the 
$\mathrm{PC}+\mathrm{SCBA}$ and placing itself in front of a fan. Gonzalez et al. [109] showed a $10 \%$ decrease in the thermal resistance of the PC of the firefighters, replacing long pants with shorts. Various studies $[110,111]$ have supported the decision to replace the uniform of the firefighters of New York City with shorts and T-shirt. In particular, Malley et al. [110] performed an exhaustion exercise on treadmill (15-20 min) in room temperature and showed that the use of shorts would make negligible the negative effect on the increase in internal temperature. The study of Chou et al. [112] examined the influence of wearing trousers or shorts under firefighting PC with phase change materials (PCMs) on physiological/subjective responses of firefighters. The results suggest that performance was improved while wearing shorts under PC with PCMs, although no significant difference in reducing thermal stress while wearing shorts instead of trousers was revealed.

\section{COGNITIVE STRAIN}

Studies on stress, due to strenuous firefighting activities performed in a hot hostile environment, showed initial impairment in cognitive function, particularly in searching for alternative solutions and making correct decision [112, $113]$.

Acute stress is a state that tends to occur in situations involving novel or infrequent problems, time pressure and high uncertainty $[114,115]$. Noise or a secondary task can reduce the attention allocated to the primary task. Gohm et al. [116] assert that affective reactions may also draw attention and influence cognitive performance. Anxiety is an uncomfortable feeling related to apprehension or worry and it is a common affective reaction to stressors in the environment.

In view of the extensive literature on the physiological aspects of the firefighters, there is limited information on stress of the psychological component related to their work activities $[3,5]$. Various studies $[117,118]$ have shown that the responses of high state anxiety, might affect cognitive functioning resulting in poor decisions. In fact, high or low levels of activation could lead to a poor performance and a considerable likelihood of injury risk during firefighters' emergencies. In fact, Kolt and Kirkby [119] claimed that the possibility of incurring an injury is increased by high levels of anxiety and stress.

Despite Smith et al. [10, 12] reporting significant increases in state anxiety during simulated emergencies, no significant change in the values of state anxiety was observed by Perroni et al. [16]. These results could be completely different in real conditions.

Previous study of Smith [10] showed that the ratio between the tympanic temperature and anxiety in high temperature condition was not significant and that although state anxiety decreased after $10 \mathrm{~min}$ post- simulated firefighting task has remained significantly elevated above pre-task. Kuorinka and Korhonen [120] showed high HR as exposure at high states of anxiety during the firefighters' operation and this result was not connected to job experience or fitness status.

\section{HORMONAL AND METABOLIC ASPECTS}

The work of firefighters is characterized by irregular events during the day and night shifts. Despite the high number of studies that have been conducted on the physiological functions of firefighting, few data $[3,5]$ are available about the hormonal responses to firefighters' activities. Studies in the literature [121-123] have highlighted the use of salivary cortisol $(\mathrm{sC})$ and salivary alpha-amylase (sA-A) as a marker of hypothalamus pituitary adrenal axis. In particular, studies have shown an increased sA-A in response to social behavior [124-126], emotions [127] and written examinations [128]. Consequently, Perroni et al. [16] have analyzed the values of $\mathrm{sC}$ and sA-A after simulated intervention. They showed higher values of sA-A in the morning of the experimental session $(102.3 \pm 18.7$ $\mathrm{U} / \mathrm{ml})$ than resting day $(\mathrm{sA}-\mathrm{A}=64.2 \pm 10.9)$ and an increase of $174 \%$ compared to pre-simulated task. The basal sC showed lower values in the morning of the experimental session $(11.3 \pm 1.9 \mathrm{nmol} / \mathrm{l})$ compared to resting day (16.7 \pm $2.2 \mathrm{nmol} / \mathrm{l})$, an increase of $108.5 \%$ after $30 \mathrm{~min}$ postintervention.

Ray et al. [3] in order to elucidate behavioral response, plasma catecholamine levels and the prevalence of neurobehavioral symptoms evaluated 62 firefighters. Compared to their colleagues not engaged in firefighting, firefighters showed higher prevalence of neurobehavioral symptoms and also a more than two-fold rise in plasma levels of epinephrine and norepinephrine indicating stimulation of sympathetic activity.

Huang et al. [129] examined the changes in HR, catecholamine, pro-inflammatory cytokines, and lymphocytes in 9 professional male firefighters participating in two counterbalanced exercise conditions on a cycle ergometer: (1) $37 \mathrm{~min}$ of cycle ergometer at $60 \% \mathrm{VO}_{2 \max }$ (exercise alone condition) and (2) $37 \mathrm{~min}$ of cycle ergometer at $60 \% \mathrm{VO}_{2 \max }$ along with $20 \mathrm{~min}$ of a computerized firefighting strategy and tactics decision-making challenge (firefighting strategy condition). Firefighting strategy condition elicited significantly greater HR, catecholamine, pro-inflammatory cytokines, and lymphocytes when compared to exercise alone condition. These elevations suggested that the addition of a mental challenge to physical stress can alter the hormonal and immunological responses during firefighting. Previously, Huang et al. [130] have examined physiological responses $\left(\mathrm{HR}, \mathrm{VO}_{2}\right.$, expiratory ventilation, blood lactate, $\mathrm{sC}$, and leg strength) to a simulated firefighter activity (stair climb) in professional firefighters wearing rubber and leather boots. Leather boots elicited significantly greater $\mathrm{SC}$ values and knee flexion time to peak torque. Furthermore, rubber boots (RB) revealed significantly greater ankle dorsi-flexion peak torque after stair climb. Blood lactate was positively related to knee flexion peak torque after stair climb in the RB. Wearing the $\mathrm{RB}$, firefighter may increase more force production and be effective at resisting fatigue. Conversely, a study of Turner et al. [131] showed that there were no significant effects of boot design (leather vs. rubber) on firefighters' metabolic and respiratory variables (minute ventilation, absolute and weight -related oxygen consumption, $\mathrm{CO}_{2}$ production, $\mathrm{HR}$, and peak inspiratory and expiratory flow rates) during simulated firefighting tasks. 


\section{TRAINING PROGRAMS}

Despite the literature provides some insight on the physical demands of firefighting and on the specific guideline for physical conditioning [60], there is a lack of scientific data regarding the identification of an appropriate physical training program that adequately prepares firefighters. In fact, study of Dennison et al. [132] demonstrated that firefighters who train regularly and possess higher fitness levels tend to perform job-specific tasks more efficiently than do untrained and lesser fit firefighters. Investigation of Swank et al. [133] indicated that a benefit could be derived from an intervention program for all firefighters designed to maintain or increase $\mathrm{VO}_{2 \max }$.

Hilyer et al. [134] have compared the effectiveness of two in-station fitness programs. One program included strength training and aerobic training equipment at each participating fire station, whereas the other program included only calisthenics and walk/run aerobic training. Firefighters who trained in stations with equipment made statistically significant improvements in four of six fitness measures. Firefighters who trained in stations without equipment did not improve their fitness measures. They suggested that the fitness improvements made by firefighters with access to equipment might be explained by: (a) greater physiological benefits, (b) motivational influence on the quantity and quality of work accomplished during the training sessions, and (c) the availability of the equipment could have influenced the amount of time spent in training during free time.

In this direction, data from study of Abel et al. [135] have indicated that a circuit-based workout may produce a similar anaerobic stress as compared to performing fire suppression and rescue tasks. They purposed that firefighters should perform high-intensity cardiovascular exercises and periodize circuit-training programs by using a range of training intensities and volumes for the aerobic and anaerobic strength/power demands of firefighting. The circuits should include 5-15 functional multi-joint exercises that simulate the movement patterns used for firefighters tasks (i.e. deadlift, stair climb with hose bundles, drag a rescue mannequin). Firefighters may be instructed to perform as many repetitions as possible within a predetermined exercise time. Brief recovery periods (i.e. 20 60 seconds) should be used between exercises, such that the work-to-rest ratio is approximately $1: 1$. Finally, it is important that the firefighters perform a warm-up, cooldown, and flexibility training during the training session.

Furthermore, various studies [23, 136] have shown that the use of fire PC impairs balance performance. Punakallio [136] showed that the postural balance was significantly poorer in the tests with the fire PC than in the baseline tests with the sportswear. For this reason, it is also essential to provide ample balance training opportunities for firefighters with and without fire PC.

Thus further research is needed to determine the influence of training on the performance and safety of fire fighters and to develop specific firefighting conditioning programs.

\section{CONCLUSION}

From analysis of the literature, we could observe how environmental, physical and emotional stress to which the firefighters are subjected during their work activities could lead to occupational hazards, injuries and even fatal events. Cardiovascular, thermal, and psychological responses deriving from the firefighters could be due to fatigue and this could compromise the health and safety of the firefighters. It is recognized that the increase in body temperature leads to a decrease in physical and mental performance. In addition, a physiological age-related decline could be expected during the occupational period of firefighters.

For these reasons, the success of job performance may depend on the ability of the firefighter to support intense physical activity. Adequate physical fitness programs and a periodic physical fitness evaluation are necessary to ensure that physically capable personnel perform this public safety occupation. A high fitness level can be crucial to the reduction of the risks inherent to the institutional activities of the firefighters.

It is useful to propose and develop initiatives relating the suitability of all firefighters through the establishment of a working group (i.e. exercise physiologists, psychologists, doctors and administrators) for the implementation of standard procedures for fitness health of all firefighters. A regular evaluation (i.e., annually) can provide a baseline for future comparison, identification deficiencies, and assistance in establishing personalized fitness and health-related goals. An adequate financial investment focused on the assessment and increase of physical capabilities of firefighters could effectively reduce the health risks linked to emergencies.

\section{CONFLICT OF INTEREST}

The authors confirm that this article content has no conflicts of interest.

\section{ACKNOWLEDGEMENT}

Declared none.

\section{REFERENCES}

[1] Gledhill N, Jamnik VK. Characterization of the physical demands of firefighting. Can J Sport Sci 1992; 17 (3): 207-13.

[2] Kales SN, Soteriades ES, Christophi CA, Christiani DC. Emergency duties and deaths from heart disease among firefighters in the United States. N Engl J Med 2007; 356(12): 1207-15.

[3] Ray MR, Basu C, Roychoudhury S, Banik S, Lahiri T. Plasma catecholamine levels and neurobehavioral problems in Indian firefighters. J Occup Health 2006; 48(3): 210-5.

[4] Bos J, Mol E, Visser B, Frings-Dresen M. The physical demands upon (Dutch) fire-fighters in relation to the maximum acceptable energetic workload. Ergonomics 2004; 15: 47(4): 446-60.

[5] Smith DL, Petruzzello SJ, Chludzinski MA, Reed JJ, Woods JA. Selected hormonal and immunological responses to strenuous livefire firefighting drills. Ergonomics 2005; 48(1): 55-65.

[6] Bilzon JL, Scarpello EG, Smith CV, Ravenhill NA, Rayson M. Characterization of the metabolic demands of simulated shipboard Royal Navy firefighting tasks. Ergonomics 2001; 44: 766-80.

[7] Oldham JA, Schofield S, McAllighan MJ, Winstanley J. An investigation of the validity of 'simulated' work-related tasks in relation to 'real life' situations in the fire service training environment. Occup Med 2000; 50: 599-607. 
[8] Petersen SR, Duncan HW, Williams BE, McGarvey WJ. The effects of hyperoxia on performance during simulated fire-fighting work. Ergonomics 2000; 43: 210-22.

[9] Smith DL, Petruzzello SJ, Kramer JM, Misner JE. Physiological, psychophysical, and psychological responses of firefighters to firefighting training drills. Aviat Space Environ Med 1996; 67: 1063-8.

[10] Smith DL, Petruzzello SJ, Kramer JM, Misner JE. The effects of different thermal environments on the physiological and psychological responses of firefighters to a training drill. Ergonomics 1997; 40(4): 500-10.

[11] Smith DL, Petruzzello SJ. Selected physiological and psychological responses to live-fire drills in different configurations of firefighting gear. Ergonomics 1998; 41(8): 114154.

[12] Smith DL, Manning TS, Petruzzello SJ. Effect of strenuous livefire drills on cardiovascular and psychological responses of recruit firefighters. Ergonomics 2001; 44(3): 244-54.

[13] Sothman M., Landy F., Saupe K. Age as a bona fide occupational qualification for firefighting: A review on the importance of measuring aerobic power. J Occup Med 1992; 34: 26-33.

[14] Sothmann MS, Saupe K, Jasenof D, Blaney J. Heart rate response of firefighters to actual emergencies. Implications for cardiorespiratory fitness. J Occup Med 1992; 34(8): 797-800.

[15] Williford HN, Duey WJ, Olson MS, Howard R, Wang N. Relationship between fire fighting suppression tasks and physical fitness. Ergonomics 1999; 42(9): 1179-86.

[16] Perroni F, Tessitore A, Cibelli G, et al. Effects of simulated firefighting on the responses of salivary cortisol, alpha-amylase and psychological variables. Ergonomics 2009; 52(4): 484-91.

[17] Perroni F, Tessitore A, Cortis C, et al. Energy cost and energy sources during a simulated firefighting activity. J Strength Cond Res 2010; 24(12): 3457-63.

[18] Knapik JJ, Sharp MA, Canham-Chervak M, Hauret K, Patton JF, Jones PH. Risk factors for training-related injuries among men and women in basic combat training. Med Sci Sports Exerc 2001; 33: 946-54.

[19] Blacker SD, Fallowfield JL, Bilzon JL, Willems ME. Neuromuscular function following prolonged load carriage on level and downhill gradients. Aviat Space Environ Med 2010; 81: 74553.

[20] Qu X, Yeo JC. Effects of load carriage and fatigue on gait characteristics. J Biomech 2011; 44:1259-63.

[21] Punakallio A, Lusa S, Luukkonen R. Protective equipment affects balance abilities differently in younger and older firefighters. Aviat Space Environ Med 2003; 74:1151-6.

[22] Selkirk GA, McLellan TM. Physical work limits for Toronto firefighters in warm environments. J Occup Environ Hyg 2004, 1: 199-212.

[23] Kincl LD, Bhattacharya A, Succop PA, Clark CS. Postural sway measurements: a potential safety monitoring technique for workers wearing personal protective equipment. Appl Occup Environ Hyg 2002; 17: 256-66.

[24] Cady LD, Thomas PC, Kawasky RJ. Program for increasing health and fitness of firefighters. J Occup Med 1985; 27: 110-4.

[25] USA. Fire Administration Fire in the United States 1995-2004. Fourteenth Editinon. Report National Fire Data Center 2007.

[26] UK Office of the Deputy Prime Minister. Medical and Occupational Evidence for Recruitment and Retention in the Fire and Rescue Service. London: Office of the Deputy Prime Minister, 2004

[27] Hammer RL, Heath EM. Comparison of aerobic capacity in annually certified and uncertified volunteer firefighters. J Strength Cond Res 2013; 27(5): 1435-40.

[28] VV.F. Statistica del Corpo Nazionale Vigili del Fuoco. Italy: Ministero dell'Interno Dipartimento dei Vigili del Fuoco del Soccorso Pubblico e della Difesa Civile 2004.

[29] Ide CW. A longitudinal survey of the evolution of some cardiovascular risk factors during the careers of male firefighters retiring from Strathclyde fire Brigade from 1985-1994. Scot Med J 2000; 45(3): 79-83.

[30] Yoo HL, Franke WD. Prevalence of cardiovascular disease risk factors in volunteer firefighters. J Occup Environ Med 2009; 51(8): 958-62.

[31] Szubert Z, Sobala W. Health reason for firefighters to leave their job. Med Pr 2002; 53(4): 291-8.
[32] Orris P, Melius J, Duffy RM. Fire-fighters' safety and health. In: Occupational Medicine: State of the Art Reviews. Philadelphia: Hanley Belfus 1995: pp. 747-62.

[33] Karter MJ, Molis JL. U. S. Firefighter Injuries-2009. Quincy, MA:NFPA Fire Analysis and Research Division 2010.

[34] Koniarek J, Dudek B. Post-traumatic stress disorder and fire fighters' attitude to their job. Med Pr 2001; 52(3): 177-83.

[35] Centers for Disease Control and Prevention. Fatalities among volunteer and career firefighters-United States, 1994- 2004. Morb Mortal Wkly Rep 2006; 55: 453-55.

[36] Fahy RF. US firefighter fatalities due to sudden cardiac death, 1995-2004. National Fire Protection Association 2005.

[37] American College of Sports Medicine. ACSM's Guidelines for Exercise Testing and Prescription, 6th ed., Philadelphia: Lippincott Williams \& Wilkins 2000

[38] Holder JD, Stallings LA, Peeples L, Burress JW, Kales SN. Firefighter heart presumption retirements in Massachusetts 19972004. J Occup Environ Med 2006; 48:1047-53.

[39] Kales SN, Soteriades ES, Christoudias SG, Christiani DC. Firefighters and on-duty deaths from coronary heart disease: a case control study. Environ Health 2003; $2: 14$.

[40] Fernhall B, Fahs CA, Horn G, Rowland T, Smith D. Acute effects of firefighting on cardiac performance. Eur J Appl Physiol 2012; 112(2): 735-41.

[41] Elsner KL, Kolkhorst FW. Metabolic demands of simulated firefighting tasks. Ergonomics 2008; 51:1418-25.

[42] Holmér I, Gavhed D. Classification of metabolic and respiratory demands in fire fighting activity with extreme workloads. Appl Ergon 2007; 38: 45-52.

[43] Dreger RW, Petersen SR. Oxygen cost of the CF-DND fire fit test in males and females. Appl Physiol Nutr Metab 2007; 32:454-62

[44] Carter JB, Banister EW, Morrison JB. Effectiveness of rest pauses and cooling in alleviation of heart stress during simulated firefighting activity. Ergonomics 1999; 42(2): 229-313.

[45] Poston WS, Haddock CK, Jahnke, SA, Jitnarin N, Tuley BC, Kales SN. The prevalence of overweight, obesity, and substandard fitness in a population-based firefighter cohort. J Occup Environ Med 2011; 53: 266-73.

[46] Durand G, Tsismenakis AJ, Jahnke SA, Baur DM, Christophi CA, Kales SN. Firefighters' physical activity:relation to fitness and cardiovascular disease risk. Med Sci Sports Exerc 2011; 43(9): 1752-9.

[47] Lowden A, Moreno C, Holmbäck U, Lennernäs M, Tucker P Eating and shift work - effects on habits, metabolism and performance. Scand J Work Environ Health Mar 2010; 36:150-62.

[48] Esquirol Y, Bongard V, Mabile L, Jonnier B, Soulat JM, Perret B. Shift work and metabolic syndrome: respective impacts of job strain, physical activity, and dietary rhythms. Chronobiol Int 2009; 26: 544-59.

[49] Kay BF, Lund MM, Taylor PN, Herbold NH. Assessment of firefighters' cardiovascular disease-related knowledge and behaviors. J Am Diet Assoc 2001; 101: 807-9.

[50] International Association of Fire Chiefs. Effects of sleep deprivation on firefighters and EMS responders: final report 2012; Available from: http://www.iafc.org/displaycommon.cfm?an 18 subarticlenbr 559

[51] Soteriades ES, Smith DL, Tsismenakis AJ, Baur DM, Kales SN, Cardiovascular disease in U.S. firefighters: a systematic review. Cardiol Rev 2011; 19: 202-15.

[52] Vilke GM, Tornabene SV, Stepanski B, et al. Paramedic selfreported medication errors. Prehosp Emerg Care 2007; 11: 80-4

[53] Puttonen S, Harma M, Hublin C. Shift work and cardiovascular disease - pathways from circadian stress to morbidity. Scand J Work Environ Health 2010; 36: 96-108.

[54] Reinhardt TE, Ottmar RD. Baseline Measurements of Smoke Exposure Among Wildland Firefighters. J Occup Environ Hyg 2004; 1: 593-606.

[55] Reisen F, Hansen D, Meyer CP. Exposure to bushfire smoke during prescribed burns and wildfires: firefighters' exposure risks and options. Environ Int 2011; 37(2): 314-21.

[56] Kales SN, Tsismenakis AJ, Zhang C, Soteriades ES. Blood pressure in firefighters, police officers, and other emergency responders. Am J Hypertens 2009; 22:11-20

[57] Violanti JM, Fekedulegn D, Hartley TA, et al. Police trauma and cardiovascular disease: association between PTSD symptoms and metabolic syndrome. Int J Emerg Ment Health 2006; 8: 227-37. 
[58] Jonsson A, Segesten K, Mattsson B. Post-traumatic stress among Swedish ambulance personnel. Emerg Med J 2003; 20: 79-84.

[59] Baur DM, Christophi CA, Tsismenakis AJ, Cook EF, Kales SN. Cardiorespiratory Fitness Predicts Cardiovascular Risk Profiles in Career Firefighters. J Occup Environ Med 2011; 53(10): 1155-60.

[60] National Fire Protection Association, NFPA Association 1500: Standard on Health-Related Fitness Programs for Fire Figthers.: National Fire Protection Association, Quincy, MA 2007.

[61] O'Connell ER, Thomas PC, Cady LD, Karwasky RJ. Energy costs of simulated stair climbing as a job-related task in fire fighting. $\mathrm{J}$ Occup Med 1986; 28: 282-4.

[62] Gledhill N, Jamnik VK. Development and validation of a fitness screening protocol for firefighter applicants. Can J Sport Sci 1992; 17: 199-206.

[63] Williams-Bell FM, Boisseau G, McGill J, Kostiuk A, Hughson RL. Physiological responses and air consumption during simulated firefighting task in a subway system. Appl Physiol Nutr Metab 2010; 35: 671-8.

[64] Eglin C, Coles S, Tipton MJ. Physiological responses of fire-fighter instructors during training exercises. Ergonomics 2004; 47(5): 48394.

[65] Richmond VL, Rayson MP, Wilkinson DM, Carter JM, Blacker SD. Physical demands of firefighter search and rescue in ambient environmental conditions. Ergonomics 2008; 51(7): 1023-31.

[66] Barnard RJ, Duncan HW. Heart rate and ECG responses of fire fighters. J Occup Med 1975; 17: 247-50.

[67] Baker SJ, Grice J, Roby L, Matthews C. Cardiorespiratory and thermoregulatory response of working in fire-fighter protective clothing in a temperate environment. Ergonomics 2000; 43(9): 1350-58.

[68] Bruce-Low SS, Cotterrell D, Jones GE. Effect of wearing personal protective clothing and self-contained breathing apparatus on heart rate, temperature and oxygen consumption during stepping exercise and live fire training exercises. Ergonomics 2007; 50: 80-98.

[69] Angerer P, Kadlez-Gebhardt S, Delius M, Raluca P, Nowak D. Comparison of Cardiocirculatory and Thermal Strain of Male Firefighters During Fire Suppression to Exercise Stress Test and Aerobic Exercise Testing. Am J Cardiol 2008; 102: 1551-6

[70] Skoldstrom B. Physiological responses of firefighters to workload and thermal stress. Ergonomics 1987; 30: 1589-97

[71] von Heimburg ED, Rasmussen AKR, Medbø JI. Physiological responses of firefighters and performance predictors during a simulated rescue of hospital patients. Ergonomics 2006; 49(2): 111-26.

[72] Rodriguez-Marroyoa JA, Villaa JG, Lopez-Satue J, et al. Physical and thermal strain of firefighters according to the firefighting tactics used to suppress wildfires. Ergonomics 2011; 54(11): 11018 .

[73] Manning JE, Griggs TR. Heart rates in fire fighters using light and heavy breathing equipment: similar near-maximal exertion in response to multiple work load conditions. J Occup Med 1983; 25 : 215-8.

[74] Eves ND, Jones RL, Petersen SR. The influence of the selfcontained breathing apparatus (SCBA) on ventilatory function and maximal exercise. Can J Appl Physiol 2005; 30: 507-19.

[75] Dorman LE, Havenith G. The effects of protective clothing on energy consumption during different activities. Eur J Appl Physiol 2009; 105: 463-70

[76] Dreger RW, Jones RL, Petersen SR. Effects of the self contained breathing apparatus and fire protective clothing on maximal oxygen uptake. Ergonomics 2006; 49: 911-20.

[77] Perroni F, Tessitore A, Lupo C, Cortis C, Cignitti L, Capranica L. Do Italian fire fighting recruits have an adequate physical fitness profile for fire fighting? Sport Sci Health 2008; 4: 27-32.

[78] Bos J, Kuijer PP, Frings-Dresen MHW. Definition and assessment of specific occupational demands concerning lifting, pushing, and pulling based on a systematic literature search. Occup Environ Med 2002; 59(12): 800-6

[79] Louhevaara V, Ilmarinen R, Griefahn B, Künemund C, Mäkinen H. Maximal physical work performance with European standard based fire-protective clothing system and equipment in relation to individual characteristics. Eur J App Physiol Occup Physiol 1995; $71(2-3)$ : 223-9.

[80] Faff J, Tutak T. Physiological responses to working with fire fighting equipment in the heat in relation to subjective fatigue. Ergonomics 1989; 32: 629-38
[81] Horowitz MR, Montgomery DL: Physiological profile of firefighters compared to norms for the Canadian population. Can J Public Health 1993; 84: 50-3.

[82] Punakallio A, Louhevaara V, Lusa-Moser S, Korhonen O. Work ability and physical fitness of fire fighters in different age groups. In: Seppala P, Luopajarvi T, Nygard C-H, Mattila M, Eds. From experience to innovation: IEA '97 Proceedings of the 13th Triennial Congress of the International Ergonomics Association; 1997 Jun 29-Jul 4, Tampere .Helsinki, Finland: Finnish Institute of Occupational Health 1997.

[83] Lemon PWR, Hermiston RT. The human energy cost of fire fighting. J Occup Med 1977; 19: 558-62

[84] Saupe K, Sothmann M, Jasenof D. Aging and the fitness of fire fighters: the complex issues involved in abolishing mandatory retirement ages. Am J Public health 1991; 81: 1192-4.

[85] Punakallio A, Lindholm H, Luukkonen R, Lusa S. Lifestyle Factors Predicting Changes in Aerobic Capacity of Aging Firefighters at 3 and 13-Year Follow-Ups. J Occup Environ Med 2012; 54(9):113341 .

[86] Wynn P, Hawdon P. Cardiorespiratory fitness selection standard and occupational outcomes in trainee firefighters. Occup Med 2012; 62: 123-128.

[87] Sawka MN, Wenger CB. Physiological responses to acute exerciseheat stress. In: Gisolfi CV, Lamb DR, Nadel ER, Eds. Perspectives in Exercise Science and Sports Medicine, Exercise Heat, and Thermoregulation. Indianapolis: Benchmark Press 1992; vol. 6: pp. 257-97.

[88] Eglin CM, Tipton MJ. Can firefighter instructors perform a simulated rescue after a live fire training exercise? Eur J Appl Physiol 2005; 95: 327-34.

[89] Ruby BC, Shriver TC, Zderic TW, Sharkey BJ, Burks C, Tysk S Total energy expenditure during arduous wildfire suppression. Med Sci Sports Exerc 2002; 34: 1048-54.

[90] Stirling M, Parsons K. The effect on dehydration state of exposure to extreme heat by trainee firefighters. Contemporary Ergonomics. In: Hanson MA, Lovesey EJ, Robertson SA, Eds. Taylor and Francis: London 1999; pp. 380-4.

[91] Duffield R, Dawson B, Bishop D, Fitzsimons M, Lawrence S Effect of wearing an ice cooling jacket on repeat sprint performance in warm/humid conditions. Br J Sports Med 2003; 37(2): 164-9.

[92] Fogarty A, Armstrong K, Gordon C, et al. Cardiovascular and thermal consequences of protective clothing: a comparison of clothed and unclothed states. Ergonomics 2004; 47(10): 1073-86.

[93] McLellan TM, Selkirk GA. Heat stress while wearing long pants or shorts under firefighting protective clothing. Ergonomics 2004; 47 (1): 75-90.

[94] Chou C, Tochihara Y, Kim T. Physiological and subjective responses to cooling devices on firefighting protective clothing Eur J Appl Physiol 2008; 104(2): 369-74.

[95] Barr D, Gregson W, Reilly T. The thermal Ergonomics of firefighting reviewed. Appl Ergon 2010; 41(1): 161-72.

[96] Taylor NAS. Challenges to temperature regulation when working in hot environments. Ind Health 2006; 44: 331-44.

[97] White MK, Hodous TK. Reduced work tolerance associated with wearing protective clothing and respirators. Am Ind Hyg Assoc J 1987; 48: 304-10

[98] White MK, Hodous TK, Vercruyssen M. Effects of thermal environment and chemical protective clothing on work tolerance, physiological responses and subjective ratings. Ergon 1991; 34: 445-57.

[99] Bishop P, Smith G, Ray P, Beaird J, Smith J. Empirical prediction of physiological response to prolonged work in encapsulating protective clothing. Ergonomics 1994; 37: 1503-12.

[100] Petruzzello SJ, Gapin JI, Snook E, Smith DL. Perceptual and physiological heat strain: Examination in firefighters in laboratoryand field-based studies. Ergonomics 2009; 52(6): 747-54.

[101] Holmér I. Protective clothing and heat stress. Ergonomics 1995; 38(1): 166-82.

[102] Pascoe D, Shanley L, Smith E. Clothing and exercise I: biophysics of heat transfer between the individual, clothing and environment Sports Med 1994; 18(1): 38-54

[103] Goldman RF. Heat stress in firefighting. Fire Eng 1990; 5: 47-53.

[104] Gonzalez-Alonso J, Mora-Rodriguez R, Below PR, Coyle EF. Dehydration markedly impairs cardiovascular function in 
hyperthermic endurance athletes during exercise. J Appl Physiol 1997; 82: 1229-36.

[105] Taylor NAS, Lewis MC, Notley SR, Peoples GE. A fractionation of the physiological burden of the personal protective equipment worn by firefighters. Eur J Appl Physiol 2012: 112(8): 2913-21.

[106] Bone B, Clark D, Smith D, Petruzzello S. Physiological responses to working in bunker gear: a comparative study. Fire Eng 1994; 147(11): 52-5.

[107] Fornell D. Understanding turnout technology: a matter of Healt and safety. Fire Eng 1992: 105-11.

[108] Stitleburg P. Improvements in gear create a few problems. NFPA J 1993: 17-18.

[109] Gonzalez RR, Levell CA, Stroschein LA, Gonzalez JA, Pandolf KB. Copper manikin and heat strain model evaluations of chemical protective ensembles for the Technical Cooperation Program (TTCP), Technical Report No. 94, Natick, MA: US Army Research Institute of Environmental Medicine 1993.

[110] Malley KS, Goldstein AM, Aldrich TK, et al. Effects of fire fighting uniform (modern, modified modern, and traditional) design changes on exercise duration in New York City firefighters. J Occup Environ Med 1999; 41: 1104-15.

[111] Prezant DJ, Freeman K, Keeley KJ, et al. Impact of a design modification in modern firefighting uniforms on burn prevention outcomes in New York city firefighters. J Occup Environ Med 2000; 42: 827-34.

[112] Chou C, Umezaki S, Son S, Tochihara Y. Effects of Wearing Trousers or Shorts under Firefighting Protective Clothing on Physiological and Subjective Responses. J Himalayan Earth Sci 2009; 12(2): 63-71.

[113] Dorner D. The logic of failure. In, Broadbent DE, Reason J. Baddeley A. Eds., Human factors in hazardous situations. Oxford: Clarendon Press 1990; pp. 463-73.

[114] Keinan G. Decision making under stress: Scanning of alternatives under controllable and uncontrollable threats. J Pers Soc Psychol 1987; 52: 639-44.

[115] Salas E, Driskell JE, Hughes S. The Study of Stress and Human Performance. Stress and human performance .In: Driskell JE \& Salas E, Eds. Mahwah, NJ: Erlbaum 1996: pp. 1-46.

[116] Gohm CL, Baumann MR, Sniezek JA. Personality in Extreme Situations: Thinking (or Not) under Acute Stress. J Res Pers 2001; 35: 388-99.

[117] Kivimaki M, Lusa S. Stress and cognitive performance of fire fighters during smoke-diving. Stress Med 1994; 10: 63-8

[118] Wu HC, Wang MJ. Determining the maximum acceptable work duration for high-intensity work. Eur J App Physiol 2001; 85: 33944.

[119] Kolt G., Kirkby R.J. Injury, anxiety, and mood in competitive gymnasts. Percept Mot Skills 1994; 78(3): 955-62.

[120] Kuorinka I, Korhonen O. Firefighters' reaction to alarm, an ECG and heart rate study. J Occup Med 1981; 23: 762-6.

[121] Viru A Viru M. Cortisol-essential adaptation hormone in exercise. Int J Sports Med 2004; 25(6): 461-4.
[122] Kivlighan KT, Granger DA. Salivary a-amylase response to competition: Relation to gender, previous experience, and attitudes. Psychoneuroendocrinology 2006; 31(6): 703-14.

[123] Li TL, Gleeson M. The effect of single and repeated bouts of prolonged cycling and circadian variation on saliva flow rate, immunoglobulin A and alpha-amylase responses. J Sport Sci 2004; 22(11-12): 1015-24.

[124] Gordis EB, Granger DA, Susman EJ, Trickett PK. Asymmetry between salivary cortisol and alpha-amylase reactivity to stress: relation to aggressive behavior in adolescents. Psychoneuroendocrinology 2006; 31(8): 976-87.

[125] Nater UM, Rohleder N, Gaab J, et al. Human salivary alphaamylase reactivity in a psychosocial stress paradigm. Int $\mathrm{J}$ Psychophysiol 2005; 55(3): 333-42.

[126] Nater UM, La Marca R, Florin L, et al. Stress-induced changes in human salivary alpha-amylase activity-associations with adrenergic activity. Psychoneuroendocrinology 2006; 31(1): 49-58.

[127] Van Stegeren A, Rohlederb N, Everaerda W, Wolf O. Salivary alpha amylase as marker for adrenergic activity during stress: Effect of betablockade. Psychoneuroendocrinology 2006; 31(1): $137-41$

[128] Skosnik PD, Chatterton RT, Swisher T, Park S. Modulation of attentional inhibition by norepinephrine and cortisol after psychological stress. Int J Psychophysiol 2000; 36(1): 59-68.

[129] Huang CJ, Webb HE, Garten RS, Kamimori GH, Evans RK, Acevedo EO. Stress hormones and immunological responses to a dual challenge in professional firefighters Int J Psychophysiol 2010; 75: 312-8.

[130] Huang CJ, Garten RS, Wade C, Webb HE, Acevedo EO Physiological responses to simulated stair climbing in professional firefighters wearing rubber and leather boots Eur J Appl Physiol 2009; 107(2): 163-8

[131] Turner NL, Sharon Chiou S, Joyce Zwiener J, Weaver C, Spahr J. Physiological Effects of Boot Weight and Design on Men and Women Firefighters J Occup Environ Hyg 2010; 7: 477-82.

[132] Dennison KJ, Mullineaux DR, Yates JW, Abel MG. The effect of fatigue and training status on firefighter performance. J Strength Cond Res 2012; 26(4): 1101-9.

[133] Swank AM, Adams KJ, Barnard KL, Berning JM, Stamford BA. Age-related aerobic power in volunteer firefighters, a comparative analysis. J Strength Cond Res 2000; 14(2): 170-4.

[134] Hilyer JC, Weaver MT, Hunter GR, Gibbs JN, Spruiell WV, InStation Physical Training for Firefighters. Strength Cond J 1999; 21(1): 60-4.

[135] Abel, MG, Mortara, AJ, Pettitt, RW. Evaluation of circuit training intensity for firefighters. J Strength Cond Res 2011; 25(10): 2895901.

[136] Punakallio A. Balance abilities of workers in physically demanding jobs: with special reference to firefighters of different age. J Sport Sci Med 2005; 4(S8): 1-47. 